\title{
Utilization of ZnS Quantum Dots for Photovoltaic Applications
}

Julio Melendres ${ }^{1,2}$, Gerardo Saavedra Rodríguez ${ }^{1}$, R. López-Delgado ${ }^{1,2}$, R.C. Carrillo-Torres ${ }^{1}$, Raúl Sánchez Zeferino ${ }^{1}$, Enrique Alvarez ${ }^{1}$ and Arturo Ayon ${ }^{2}$

${ }^{1 .}$ Universidad de Sonora, Departamento de Física, Hermosillo, México.

2. University of Texas at San Antonio, Physics and Astronomy, San Antonio, USA.

There is a current trend to reduce the environmental impact of $\mathrm{CO}_{2}$ emissions from fossil fuel consumption by promoting the utilization of clean and renewable energy sources[1], more specifically through the use of solar cells as an alternative to satisfy global energy requirements. Solar cells have become a major topic in research and development in recent years due to the interest of green sustainable schemes for energy harvesting. For this purpose nanotechnology is considered a suitable approach for designing and developing solar cells that comprising better and more efficient materials. In this work we present the synthesis of Zinc Sulfide $(\mathrm{ZnS})$ Quantum Dots (QDs) coated with PolyvinylPyrrolidone (PVP) in a colloidal solution employing a double replacement reaction in aqueous solution[2] $\mathrm{Zn}\left(\mathrm{NO}_{3}\right)_{2}+\mathrm{Na} 2 \mathrm{~S}+\mathrm{PVP} \rightarrow \mathrm{PVP}-\mathrm{ZnS}+2 \mathrm{NaNO}_{3}$, and their deployment on the window side of commercial solar cells to quantify their influence on power conversion efficiency (PCE). The PVP concentration was employed to control the final quantum dot size attained which had a range in diameter from 4.9 to $5.9 \mathrm{~nm}$. Subsequently the QDs were dispersed in Polymethyl Methacrylate Polymer (PMMA) and the solution was spin cast[3] on the window side of previously characterized solar cells. The observations indicated a promising increment of $6.62 \%$ in the power conversion efficiency of the devices involved. We therefore discuss the synthesis and characterization of ZnS QDs coated with PVP for photovoltaic applications.

References:

[1] M. Z. Jacobson et al, Energy Environ. Sci. 8 (2015), p. 2093.

[2] A. K. Shahi et al, Electron. Mater. Lett. 13 (2017), p. 160.

[3] P. Temple-Boyer et al, Microelectron. Eng. 87 (2010), pp. 163.
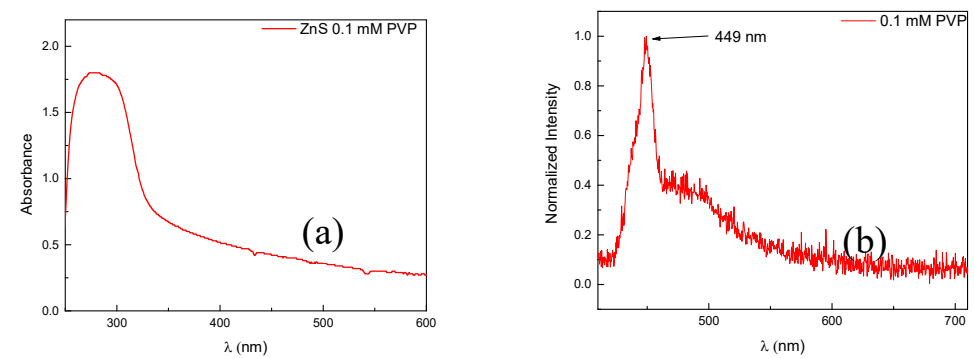

Figure 1. Absorbance (a) and Photoluminescence emission (b) under $325 \mathrm{~nm}$ excitation of ZnS QD's with PVP coating. 

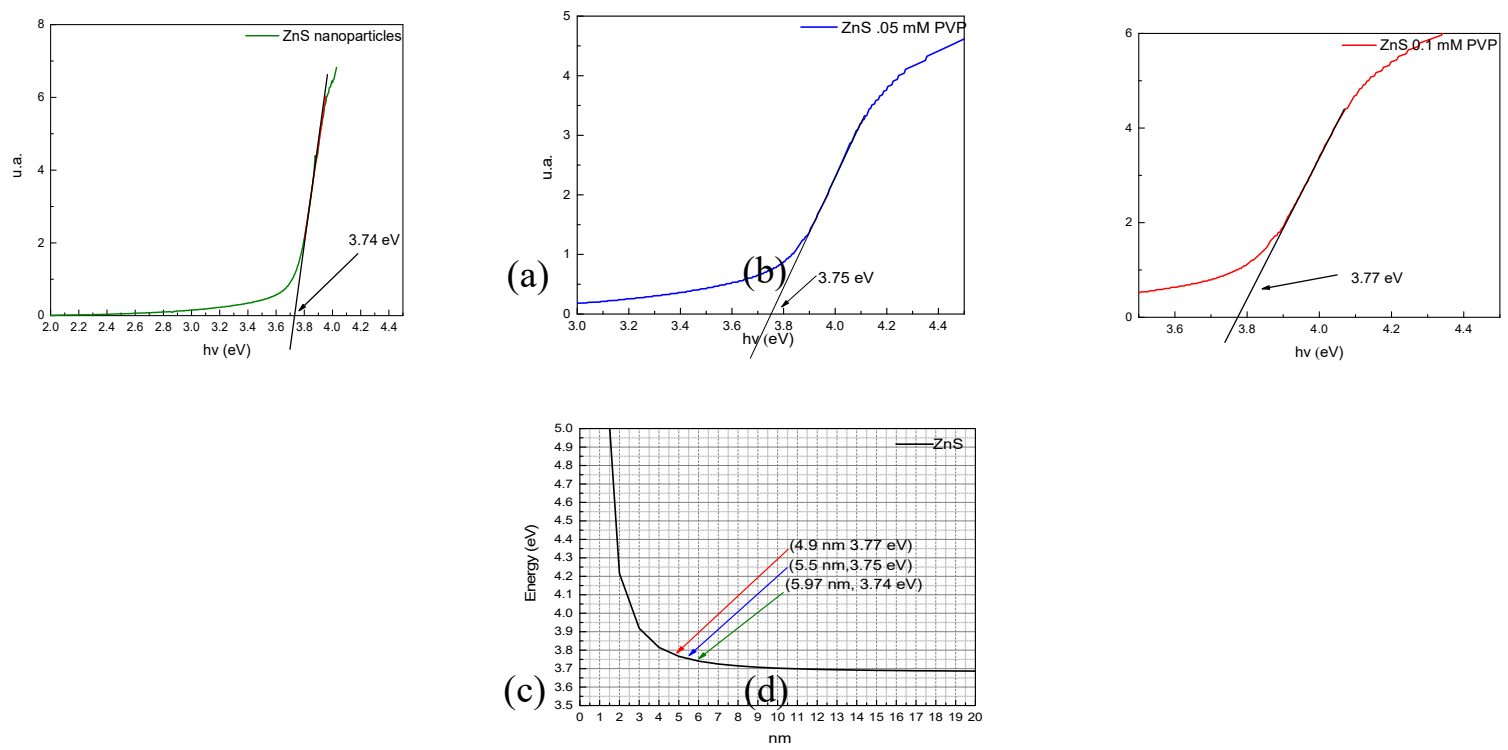

Figure 2. a) through c) are graphs of bandgap determination of the synthetized ZnS Quantum Dots with a) No PVP coating b) using $0.05 \mathrm{mM}$ of PVP coating and c) $0.1 \mathrm{mM}$ of PVP coating using Tauc's plot. d) Graph of the previously obtained bandgap values, used to estimate quantum dot size using Brus' equation as a reference.

\begin{tabular}{|l|c|c|c|c|c|c|}
\hline \multirow{2}{*}{} & \multicolumn{2}{|c|}{ ZnS 0 mM PVP } & \multicolumn{2}{c|}{ ZnS 0.05 mM PVP } & \multicolumn{2}{c|}{ ZnS 0.1 mM PVP } \\
\cline { 2 - 7 } & BEFORE & AFTER & BEFORE & AFTER & BEFORE & AFTER \\
\hline $\mathrm{V}_{\text {OC }}(\mathrm{V})$ & 0.62 & 0.62 & 0.64 & 0.64 & 0.61 & 0.61 \\
\hline $\mathrm{J}_{\mathrm{SC}}\left(\mathrm{mA} / \mathrm{cm}^{2}\right)$ & 35.68 & 35.427 & 36.1 & 36.37 & 35.48 & 36.09 \\
\hline FF $(\%)$ & 64.51 & 66.41 & 68.2 & 69.67 & 66.85 & 70.19 \\
\hline PCE $(\%)$ & 14.46 & 14.64 & 15.85 & 16.24 & 14.66 & 15.63 \\
\hline
\end{tabular}

Figure 3. Comparison of commercial solar cells characterized before quantum dot deployment and after being coated with a) ZnS Quantum Dots without PVP b) ZnS Quantum Dots with 0.05 mM PVP and c) ZnS Quantum Dots with $0.1 \mathrm{mM}$ of PVP. 